\title{
Assessment of tissue reaction of rat to materials used in vascular grafts.
}

\author{
Gholam Hosein Kazemzadeh ${ }^{1}$, Nafiseh Jirofti ${ }^{2}$, Davod Mohebbi-Kalhori ${ }^{2}$, Reza Taheri ${ }^{3 *}$ \\ ${ }^{1}$ Department of Vascular Surgery, Vascular and Endovascular Surgery Research Center, Mashhad University of Medical \\ Sciences, Mashhad, Iran \\ ${ }^{2}$ Department of Chemical Engineering, University of Sistan and Baluchestan, Zahedan, Iran \\ ${ }^{3}$ Surgical Oncology Research Center, Mashhad University of Medical Sciences, Mashhad, Iran
}

\begin{abstract}
Background: Vascular grafts are used common in surgery. Some patients have no native vessels for autograft so we should use vascular graft. In this study we assessed tissue reaction of rats to materials used in vascular grafts.

Materials and methods: We prepared 8 types of grafts with electro-spinning method from different materials such as polycaprolactone (PCL), polyurethane (PU) and polyethylene terephthalate (PET) in sporadic and mixture patterns. After sterilisation with ethylene oxide, grafts were implanted in subcutaneous layer of 32 rats (divided into 8 groups of 4 rats). Rats assessed for local and general responses in $45 \mathrm{~d}$. Histopathological responses were assessed by pathologist after $45 \mathrm{~d}$.

Results: There is no mortality during study. There are no local and systemic responses. Surgical site Infection not found. Tissue reactions to polyethylene terephthalate (PET) was higher than PET (Bio). Tissue reactions to polyurethane (PU) and PU (Bio) were about equal. PU had lower reactions in comparison with (PET) and polycaprolactone (PCL). PU+PET (Bio) had lower reaction in comparison with PET+PCL (Bio)

Conclusions: It seems polyurethane has lesser reaction in compared with other materials in both single and mixture
\end{abstract}

Keywords: Rat, Electro-spinning, Vascular graft, Tissue reaction.

Accepted on June 11, 2018

\section{Introduction}

Biomaterial implants are used in different anatomic locations. It has been recognized that maintaining a controlled biological reaction in the peri-implant region is essential. Although the ultimate device designs are regularly used in their target anatomical location, the biocompatibility of polymer components is often evaluated subcutaneously or intramuscularly. Subcutaneous tissue implant in the rat model has proven to be a high-throughput, relatively low-cost screening technique for testing tissue responses to new materials $[1,2]$.

The healing characteristics surrounding polymer implants in subcutaneous tissues are often extrapolated to other tissues; expecting that the observed healing is similar in other locations. This model also allows the initial evaluation of the effects of materials used in vascular grafts on tissue responses in a more relevant environment than the in vitro assay. The aim of this study was to assess the tissue reaction to materials used in vascular grafts in the rat model.

\section{Materials and Methods}

This research has started in 2015. We contributed to the planning, design, gathering, analysis and interpretation of all data about artificial vessels. In this team working project, research group from Sistan and Balouchestan University started making artificial vessels by electro-spinning method since 2015. We use nano technique for production of artificial vessel. We product nano fiber by electro-spinning; this method have many advantages such as scalability, repeatability and control of nano fiber diameter; One reason for usage of nano fiber is that red blood cells cannot transmit from their holes. The electro-spinning method was used first to manufacture eight samples of multi-layer and single layer polycaprolactone (PCL), polyurethane (PU) and polyethylene terephthalate (PET) biopolymer nano-fibers. For assessment histopathological response to substances used in tissue vascular grafts rats were chosen. Coordination with the animal lab Mashhad medical faculty was done to provide rat. The rats were about $45 \mathrm{~d}$ old and had the mean weight of $170 \mathrm{gm}$. After ensuring proper preparation of rats, artificial blood samples with ethylene oxide in the clean sterile room (CSR) were sterile for $14 \mathrm{~h}$. Rats with a mixture of ketamine $(1.5 \mathrm{cc})$ and 
xylazine $(0.7 \mathrm{ml})$ were anesthetized by intraperitoneal way. 3 rats died after anaesthesia and before planting tissue. The rats were wound on the right side. First was shaved with a razor and location was prepared with povidone-iodine. $8 \mathrm{~mm}$ was a cut on the skin. Subcutaneous were explored with sterile scissors. The sample size ( 8 of $8 \mathrm{~mm}$ ) implanted in the subcutaneous with forceps. Skin was sutured with 5 zero nylon. Of each sample tissue was implanted four. The duration of anaesthesia was about 20 to $25 \mathrm{~min}$ for each rat. Every four rats were placed inside a shelf. From each group a sample photo was taken from the planting site. In the first $10 \mathrm{~d}$ rats were assessed of mortality, local and systemic reactions and wound infection daily and were also photographed. In the second decade monitored every $2 \mathrm{~d}$ and in the third and fourth decade were monitored every $3 \mathrm{~d}$. After $45 \mathrm{~d}$ the end-stage test was conducted on. 32 biopsy dishes were prepared. $30 \mathrm{cc}$ Formalin was poured into each dish. Then was marked on the tail of rats; Cage with 8 rats were placed inside black plastic. The animals were killed with carbon dioxide gas; then shaved the site of implanted artificial scaffold. Photos were taken from the planting site. Then proceed to cut skin

When the artificial vessel was found, second photo was taken. The artificial scaffold with surrounding tissue was removed and transferred to biopsy dishes. The rats were transferred to the bag for disposing. Samples were transferred to the Department of Pathology, Ghaem Hospital according to prior coordination. After fixation and cutting samples were observed by pathology expert; The Mashhad Medical University Institutional Research Ethics Committee approved all animal experiments.

\section{Results}

There is no mortality during study. There are no local and systemic responses. Surgical site infection was not found. Infiltration, edema, prominent vessels, fibrosis and granulomatous reaction assessed by pathologist. The results are shown in Table 1. Tissue reactions to polyethylene terephthalate (PET) was higher than PET (Bio). Tissue reactions to polyurethane (PU) and PU (Bio) was about equal.

PU had lower reactions in comparison with (PET) and polycaprolactone (PCL).

PU+PET (Bio) had lower reaction in comparison with PET + PCL (Bio) and PU+PCL (Bio).

Table 1. Tissue reaction of rat to materials used in vascular grafts.

\begin{tabular}{llllll}
\hline Sample & $\begin{array}{l}\text { Infiltratio } \\
\mathbf{n}\end{array}$ & Edema & $\begin{array}{l}\text { Promine } \\
\mathbf{n t} \\
\text { vessels }\end{array}$ & $\begin{array}{l}\text { Fibrosi } \\
\mathbf{s}\end{array}$ & $\begin{array}{l}\text { Granulomatou } \\
\text { s reaction }\end{array}$ \\
\hline $\begin{array}{l}\text { Polyethylene } \\
\text { Terephthalate } \\
\text { (PET) }\end{array}$ & Moderate & Mild & Moderate & Severe & Severe \\
\hline PET(Bio) & Mild & $\begin{array}{l}\text { Mild to } \\
\text { moderat } \\
\text { M }\end{array}$ & Mild & $\begin{array}{l}\text { Mild to } \\
\text { moderat Without to mild } \\
\text { e }\end{array}$ & \\
\hline
\end{tabular}

\begin{tabular}{|c|c|c|c|c|c|}
\hline $\begin{array}{l}\text { Polyurethane } \\
\text { (PU) }\end{array}$ & Mild & Mild & Mild & $\begin{array}{l}\text { Moderat } \\
\mathrm{e}\end{array}$ & Mild \\
\hline PU (Bio) & Moderate & Mild & Moderate & Mild & Mild \\
\hline $\begin{array}{l}\text { Polycaprolacto } \\
\text { ne (PCL) Bio }\end{array}$ & Mild & Severe & Moderate & Mild & Mild \\
\hline $\begin{array}{l}\text { PET+PCL } \\
\text { (Bio) }\end{array}$ & Mild & Mild & Mild & $\begin{array}{l}\text { Mild to } \\
\text { moderat } \\
\mathrm{e}\end{array}$ & $\begin{array}{l}\text { Severe (in one } \\
\text { sample } \\
\text { Abscess) }\end{array}$ \\
\hline PU+PCL (Bio) & Mild & $\begin{array}{l}\text { Moderat } \\
\mathrm{e}\end{array}$ & Mild & Mild & Moderate \\
\hline PU+PET (Bio) & Mild & Mild & Mild & Mild & Without \\
\hline
\end{tabular}

\section{Discussion}

Various materials have been used in vascular grafts in order to replace or bypass a damaged or occluded vessel, but regarding the ideal material, there is no consistency in different studies. Although the popularity of endovascular surgery has increased over the recent years, vascular bypass grafting has remained commonplace and is still the optimal choice for patients requiring long-term revascularization. Currently, the preferred conduits for vascular grafting are autologous arteries or veins. The availability of autologous vessels might be limited, their quality may be poor and their extraction causes donor site morbidity [3-5]. Synthetic vascular grafts are also available as an alternative to autologous vessels. All types of grafts cause tissue reactions after they are implanted. Our study was conducted in order to compare the tissue reactions in rat after contact with three different prosthetic materials used in the synthetic vascular grafts in solitary or mixture patterns.

In this study, polycaprolactone (PCL), polyurethane (PU) and polyethylene terephthalate (PET) were chosen. Generally it is accepted that subcutaneous implantation using small animal models is suitable to primarily assess the effects of biomaterials [6]. Klinge et al. studied foreign-body reaction to mesh materials and showed a persistent foreign-body reaction that is independent of implantation time, but varies according to the type of material [7]. Excessive and chronic inflammation is a known factor contributing to implant failure [8]. Torneck showed that subsequent to the implantation of polyethylene tubes, fibrous tissue repair occurred and no inflammation was seen [9]. In the current study, tissue reactions to polyethylene terephthalate (PET) was higher than PET (Bio). Tissue reactions to polyurethane (PU) and PU (Bio) was about equal. PU had lower reactions in comparison with (PET) and polycaprolactone (PCL). PU+PET (Bio) had lower reaction in comparison with PET+PCL (Bio). It seems that polyurethane has lesser reaction in compared with other materials in both single and mixture patterns. Further studies about the other behaviours and mechanisms of action of this material will be necessary.

\section{Acknowledgment}

The results described in this paper constituted as a part of the thesis submitted by the last author to Mashhad University of Medical Sciences. This study was supported by the vice 
chancellor for research at Mashhad University of Medical Sciences and the National Institute for Medical Research.

\section{References}

1. Sharkawy AA, Klitzman B, Truskey GA, Reichert WM. Engineering the tissue which encapsulates subcutaneous implants. I. Diffusion properties. J Biomed Mater Res 1997; 37: 401-412.

2. Mako WJ, Shah A, Vesely I. Mineralization of glutaraldehyde-fixed porcine aortic valve cusps in the subcutaneous rat model: analysis of variations in implant site and cuspal quadrants. J Biomed Mater Res 1999; 45: 209-213.

3. Klinkert P, Post PN, Breslau PJ, van Bockel JH. Saphenous vein versus PTFE for above-knee femoropopliteal bypass. A review of the literature. Euro J Vasc Endovasc Surg 2004; 27: 357-362.

4. Chew DK, Owens CD, Belkin M, Donaldson $\mathrm{MC}$, Whittemore AD, Mannick JA. Bypass in the absence of ipsilateral greater saphenous vein: safety and superiority of the contralateral greater saphenous vein. J Vasc Surg 2002; 35: 1085-1092.

5. Taylor LM, Edwards JM, Brant B, Phinney ES, Porter JM. Autogenous reversed vein bypass for lower extremity ischemia in patients with absent or inadequate greater saphenous vein. Am J Surg 1987; 153: 505-510.

6. Morse DR, Wilcko JM, Pullon PA, Furst ML, Passo SA. A comparative tissue toxicity evaluation of the liquid components of gutta-percha root canal sealers. J Endodontics 1981; 7: 545-550.

7. Klinge U, Klosterhalfen B, Muller M, Schumpelick V. Foreign body reaction to meshes used for the repair of abdominal wall hernias. Euro J Surg 1999; 165: 665-673.

8. Anderson JM. Inflammatory response to implants. ASAIO Transactions 1988; 34: 101-107.

9. Torneck CD. Reaction of rat connective tissue to polyethylene tube implants. Oral Surg, Oral Med, Oral Pathol 1966; 21: 379-387.

\section{*Correspondence to}

Reza Taheri

Surgical Oncology Research Center

Mashhad University of Medical Sciences

Mashhad

Iran 